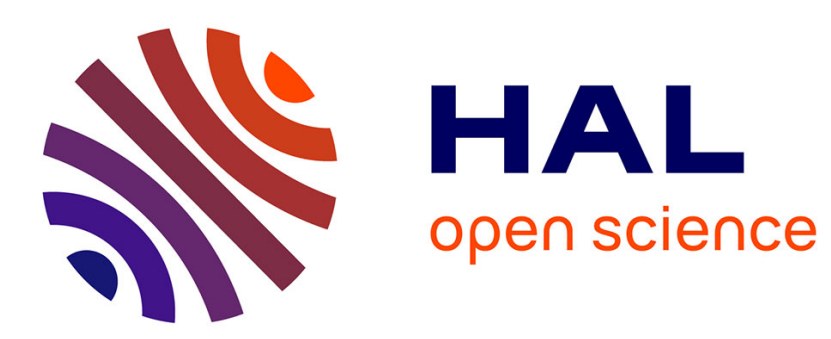

\title{
Phase Relationship of Photodetected Signals of an Optical Feedback Interferometry Sensor
}

Jalal Al Roumy, Julien Perchoux, Thierry Bosch

\section{To cite this version:}

Jalal Al Roumy, Julien Perchoux, Thierry Bosch. Phase Relationship of Photodetected Signals of an Optical Feedback Interferometry Sensor. Lasers and Electro-Optics Pacific Rim (CLEO-PR), 2015 11th Conference on, Aug 2015, Busan, South Korea. hal-01259863

\section{HAL Id: hal-01259863 https://hal.science/hal-01259863}

Submitted on 21 Jan 2016

HAL is a multi-disciplinary open access archive for the deposit and dissemination of scientific research documents, whether they are published or not. The documents may come from teaching and research institutions in France or abroad, or from public or private research centers.
L'archive ouverte pluridisciplinaire HAL, est destinée au dépôt et à la diffusion de documents scientifiques de niveau recherche, publiés ou non, émanant des établissements d'enseignement et de recherche français ou étrangers, des laboratoires publics ou privés.

\section{(ㅇ)(1) $\$$}

Distributed under a Creative Commons Attribution - NonCommercial - NoDerivatives| 4.0 


\title{
Phase Relationship of Photodetected Signals of an Optical Feedback Interferometry Sensor
}

\author{
Jalal Al Roumy ${ }^{1,2}$, Julien Perchoux ${ }^{1,2}$, and Thierry Bosch ${ }^{1,2}$ \\ 1. CNRS, LAAS, 7 Avenue du Colonel Roche, F-31077 Toulouse Cedex 4, France \\ 2. Univ de Toulouse, INP, LAAS, F-31400 Toulouse, France \\ jalal.alroumy@enseeiht.fr
}

\begin{abstract}
Optical Feedback Interferometry signals can be acquired by photodetection either from rear or front facet of the laser. We present a model that links both signals to the injection current. The comparison with experimental results validates the model.
\end{abstract}

\section{INTRODUCTION}

Optical feedback interferometry (OFI) is a well-known sensing technique where the back-scattered light from a distant target is re-injected into the laser cavity thus producing variation of the laser emitted power. OFI signals can be obtained by observation of the fluctuations in the output power either through the monitoring photodiode usually displayed in front of the laser rear facet (called rear PD signal) or through a photodiode that collects a part of the power emitted trough the front facet of the laser (called front PD signal) while using a beam splitter placed in the optical path between the front facet and the target as shown in Fig. 1.

The rear and front PD signals were first reported to be out-of-phase by Juskaitis et al [1], with clearer observations and better reasoning provided by Wang et al [2] and Randone et al [3]. In this paper, we present modeling results based on a previous work reporting the evolution of the PD signal with the injection current [4]. The developed model was validated experimentally over the entire injection current range.

\section{TheORETICAL MODEL}

Considering the schematic representation of OFI configuration shown in Fig. 2, interferometric signals can be observed in two different positions: using the electric field that propagates from the active cavity through the rear facet and is acquired by the rear photodiode, $E_{b}$, and the electric field that propagates through the front facet $E_{f}$. In the presence of a remote target, part of the backreflected electric field is reflected from the laser front facet back towards the target (denoted as $E_{\text {ref }}$ ). $E_{f}$ and $E_{\text {ref }}$ are acquired by the front photodiode.

Solving Lang and Kobayashi equations [5] for both $E_{b}$ and $E_{f}$, leads to the classical OFI equations

$$
\begin{aligned}
& P_{b}=P_{b_{0}}\left[1+m \cdot \cos \left(\omega \cdot \tau_{e x t}\right)\right] \\
& P_{f}=P_{f_{0}}\left[1+m \cdot \cos \left(\omega \cdot \tau_{e x t}\right)\right]
\end{aligned}
$$

where $P_{b}$ and $P_{f}$ are the power under feedback at the back facet and the front facet respectively, $P_{b 0}$ and $P_{f 0}$ are the corresponding power of the solitary laser diode, $m$ is the power modulation index, $\omega$ is the angular lasing frequency, and $\tau_{\text {ext }}$ is the round-trip time delay in the external cavity.

While on the rear PD, only $E_{b}$ must be considered, on the front $\mathrm{PD}$ both $E_{b}$ and $E_{\text {ref }}$ are mixed leading to interferences so that the optical power photodetected $P_{\text {front }}$ is

$$
P_{\text {front }}=P_{f_{0}}\left[1+\left(m-2 \sqrt{R_{2} \cdot R_{\text {ext }}}\right) \cos \left(\omega \cdot \tau_{\text {ext }}\right)\right]
$$

where $R_{2}$ is the power reflectivity of the front facet and $R_{\text {ext }}$ is the effective power reflectivity of the remote target.

The ratio of the modulation indices of the front and rear PD signals, $M_{R}$, can be expressed as

$$
M_{R}=1-\frac{\tau_{l}}{\tau_{p}} \cdot \frac{R_{2}}{T_{2}} \cdot \frac{I-I_{t h}}{I-I_{t r}}
$$

where $\tau_{l}$ is the round-trip time delay within the active cavity, $\tau_{p}$ is the photon lifetime, $T_{2}$ is the front facet power transmission coefficient, $I$ is the injection current, $I_{\text {th }}$ and $I_{\text {tr }}$ are the currents at threshold and transparency, respectively.

Expression (4) explicitly shows the evolution of the modulation indices ratio with injection current. Just above threshold, the ratio is positive, and then it gradually decreases with the increment of injection current until it becomes zero indicating no detection of the front signal. Further increment of the current leads to a negative ratio as the front PD signal changes sign. At high injection currents, the ratio becomes almost constant.

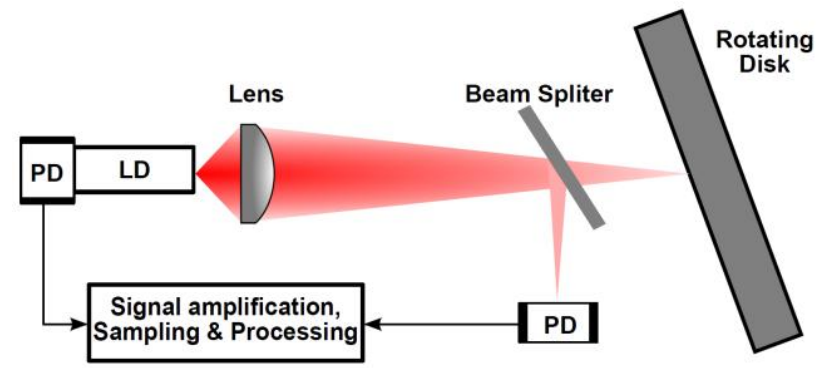

Fig. 1. Experimental set up for the measurements of PD signals.

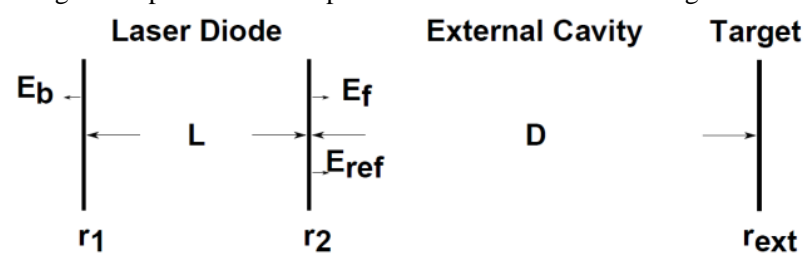

Fig. 2. Schematic model for the phase relationship analysis. 


\section{RESUlTS AND DISCUSSION}

In order to experimentally validate the developed analytical model, set of experiments were performed using the OFI sensor in the Doppler velocimeter configuration as shown in Fig. 1. The laser diode used was DFB laser (ML725B11F, $\lambda=1310 \mathrm{~nm}$ ).

Fig. 3 shows both PD signals measured at different values of injection current. In Fig. 3(a), both signals are in-phase at $6 \mathrm{~mA}$. Increasing the injection current to 9 $\mathrm{mA}$, the front PD signal vanishes and is reduced to the noise level, as shown in Fig. 3(b). Further increment of injection current leads to the sign inversion of the front signal as shown in Fig. 3(c).

The model was simulated using the intrinsic laser parameters given in [6]. The theoretical curve in Fig. 4 that we obtain after minor fitting of the ratio of the reflectivity and transmission coefficients shows good agreement with the measurements.

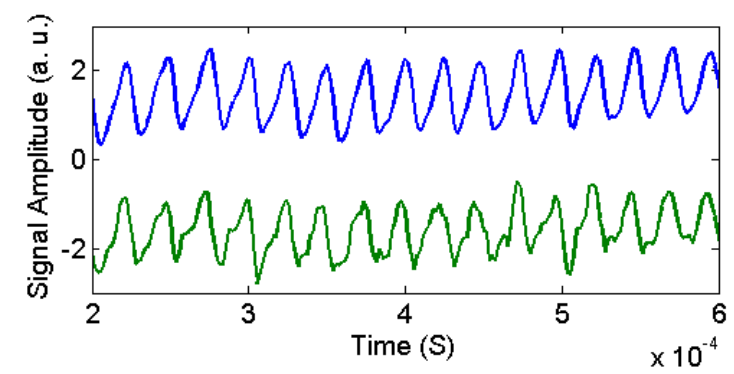

(a)

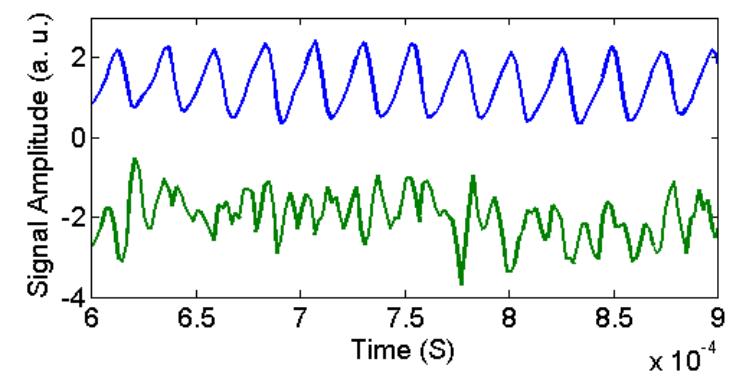

(b)

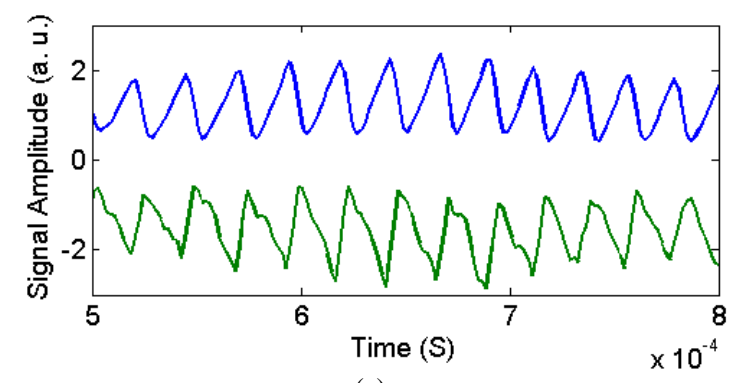

(c)

Fig. 3. Normalized rear (upper blue trace) and front (lower green trace) PD signals at different bias currents: a) $I=6 \quad \mathrm{~mA}$, PD signals are in-phase, b) $I=9 \mathrm{~mA}$, front $\mathrm{PD}$ signal vanishes, c) $\mathrm{I}=16 \mathrm{~mA}$, signals are out-of-phase.

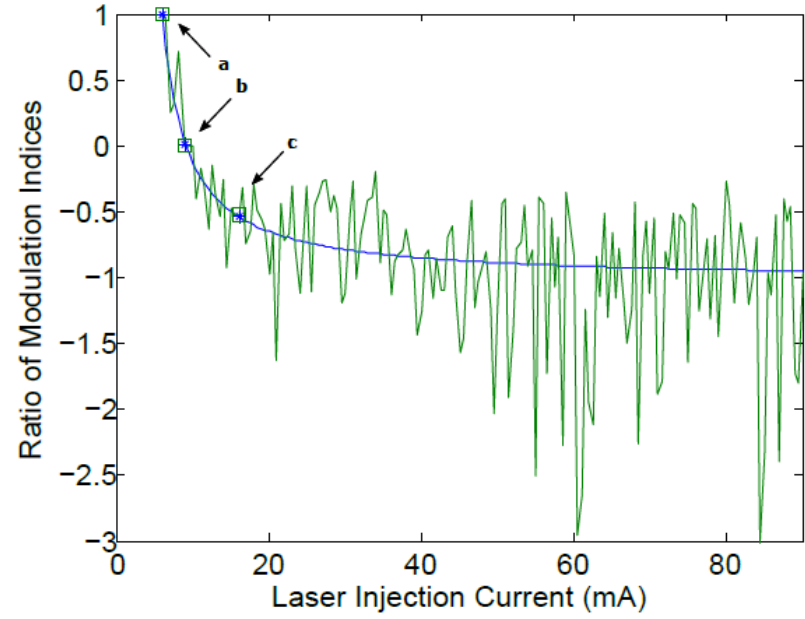

Fig. 4. Ratio of modulation indices as function of injection current: measured (green solid), and modeled (blue solid). The bias currents at which signals in Fig. 3 were measured are marked.

\section{CONCLusions}

An analytical model describing the phase and amplitude relationship of PD signals acquired through rear and front facet of the laser diode in while subject to optical feedback was presented and validated experimentally. The model explains well the observed phase inversion of the front PD signal as well as the inability to detect the signal at some point along the injection current range. This bias current can be either avoided when using an external photodetector in optical feedback interferometric application or considered when optical feedback is undesired.

\section{ACKNOWLEDGMENT}

This research was supported under Campus France and the Conseil Régional de Midi-Pyrénées funding program.

\section{REFERENCES}

[1] R. Juskaitis, N. P. Rea, and T. Wilson, "Semiconductor laser confocal microscopy," Appl. Opt. 33, 578-584 (1994).

[2] W. Wang, W. J. O. Boyle, K. T. W. Grattan, and A. W. Palmer, "Self-mixing interference in a diode laser for optical sensing applications," IEEE J. Lightwave Technol. 12, 157-1587 (1992).

[3] E. M. Randone and S. Donati, "Self-mixing interferometer: analysis of the output signals," Opt. Express 14, 9788-9796 (2006).

[4] J. Al Roumy, J. Perchoux, Y. L. Lim, T. Taimre, A. D. Rakić, and T. Bosch, "Effect of injection current and temperature on signal strength in a laser diode optical feedback interferometer," Appl. Opt. 54, 312-318 (2015).

[5] R. Lang and K. Kobayashi, "External optical feedback effects on semiconductor injection laser properties," IEEE J. Quantum electron. 16, 347-355 (1980).

[6] L. A. Coldren, S. W. Corzine, and M. L. Mashanovitch, Diode Lasers and Photonic Integrated Circuits, 2nd ed. (Wiley, 2012). 